\title{
Video for peer feedback and reflection: embedding mainstream engagement into learning and teaching practice
}

\author{
Lindsay Jordan* \\ Centre for Learning and Teaching in Art and Design, University of the Arts London, \\ High Holborn, London, UK
}

(Received 12 March 2012; final version received 30 June 2012)

\begin{abstract}
This paper discusses the benefits and challenges of video as a tool for supporting and enhancing peer feedback and reflection. The analysis draws on key arguments from relevant literature in combination with the author's own experiences of producing and using video recordings of peer feedback sessions, presentations and personal reflections, and on learners' experiences of the same, gathered through feedback interviews. A number of potential benefits are presented, including the exposure of additional and alternative perspectives, the assistance of focus and recall, increased impact and greater flexibility of learning. Several challenges are also explored, such as privacy of and access to recordings, participant anxiety, technical challenges and access to hardware. Strategies are offered for capitalising on the benefits while addressing the challenges. It is concluded that thoughtful use of video in the curriculum can augment the existing multiple benefits of reflection, enquiry and/or evaluation. In the specific context of teacher education, it is argued that the embedded use of technologies such as video in professional development courses can help to develop the digital literacy of teaching staff.
\end{abstract}

Keywords: effectiveness; ethics; staff development; handheld devices; peer feedback

\section{Introduction}

The teaching and learning context of this paper is the Academic Practice Provision (APP), a portfolio of units offered by the Centre for Learning \& Teaching in Art \& Design (CLTAD) at the University of the Arts London (UAL). The APP allows participants to gain credit towards an initial teaching qualification - the Postgraduate Certificate ("PG Cert") - and further qualifications up to a full Master's degree. The majority of APP participants are practicing teachers working across a variety of art and design disciplines, and the extent of their own teaching experience generally ranges from 2 to 30 years.

The design of the units that make up the APP is informed by established pedagogic principles (such as constructive alignment and reflective practice), and emerging priorities such as open practice and the development of digital literacies. The use of video was introduced to participants with the aim of not only supporting peer feedback and personal reflection, but also to provide teachers with positive experiences of using these tools so that they are encouraged and empowered to use these methods where appropriate in their own teaching practice.

*Corresponding author. Email: lindsay.jordan@arts.ac.uk 


\section{Methods used}

This paper discusses the use of video for the recording of peer feedback sessions and the presentation of reflective assignments. To set the scene, a brief summary of the wider and historical use of video in education will precede a review of the literature around the role of peer feedback in learning and the factors contributing to productive reflection. A theoretical basis for the use of video in these contexts will be proposed. To conclude the review of literature the issue of digital literacy, and its relevance in this context, will be explored with reference to recent studies. The use of video for the recording of peer feedback (e.g. http://www.vimeo.com/18707631) and the presentation of reflective assignments (e.g.: http://www.vimeo.com/24828893) will then be discussed with reference to this body of literature, and drawing on the author's own experience and on feedback from participants on the APP.

\section{Review of relevant literature}

\section{The use of video in education}

The use of video among the general population has risen dramatically over the last few years with the advent of video-sharing tools such as Youtube (www.youtube.com) and Vimeo (www.vimeo.com), faster internet speeds and the increasing capability of mobile devices to capture good-quality moving image. As general use of video rises across a broad range of applications, its prevalence in specific professional and educational contexts has also increased. The use of video for presenting educational content is now widespread; from the popular Technology, Entertainment, Design (TED) series (www.ted.com) to both commercial and open initiatives such as Lynda software screencasts (www.lynda.com) and The Khan Academy math tutorials. Video has also been used for many years as a tool for teacher training commonly for recording the teaching of micro-sessions in order to enhance feedback (Allen and Ryan 1969).

This paper, while also situated in the context of teacher education, looks not at video as a tool for recording teaching, but for recording feedback exchanged among learners. The fact that the learners in this context also happen to be teachers is largely incidental, although relevant in terms of wider aims and potential impact.

\section{The role of peer feedback in learning}

\section{Developing transferable skills in self-regulation}

Nicol and Macfarlane-Dick (2006) argue that "formative assessment and feedback are still largely controlled by and seen as the responsibility of teachers" (p. 200). However, the authors go on to demonstrate that learners are fully capable of assessing their own work and that the Higher Education sector needs to do more to ensure that learners develop transferable self-regulation skills. McConnell (2002) supports this view, pointing out that peer assessment allows learners to develop skills that they can use to assess their own learning and that (citing Boud 2000), "equipping learners with such skills should be a key aspect of the so-called learning society" (p. 89).

\section{Meaningful, actionable feedback}

Ivanic et al. (2000 cited in Nicol and Macfarlane-Dick 2006) argue that learners need to construct their own understanding of feedback (e.g. through dialogue) in order to 


\section{Jordan}

act upon it. Eliciting feedback in an open, discursive peer-group situation provides the opportunity for learners to take away feedback that is both meaningful to them and immediately actionable.

\section{Motivation and demotivation}

Crooks (1998) proposes that co-operative peer assessment that is well designed and prepared for can not only facilitate learning and motivation, but also help to develop interpersonal skills and relationships between students.

\section{The role of video in reflective learning}

In Becoming a Critically Reflective Teacher (1995), Stephen Brookfield states that becoming aware of who we are and what we do is "a puzzling and contradictory task ... we find it very difficult to stand outside ourselves" (p. 28). Brookfield's description of this as "the pedagogic equivalent of trying to see the back of one's head while looking in the bathroom mirror" (p. 29) is worth noting as a video camera is in fact a very effective way of - both figuratively and literally - viewing the back of one's head. Seeing ourselves on video for the first time challenges comfortable and familiar ideas we hold about ourselves, and can therefore be an unpleasant experience. In Brookfield's view, assumption-searching behaviour (such as videoing oneself) "is often deliberately avoided for fear of what it might lead to" (p. 29). In other words, as long as we can remain unaware of something that needs our attention, we can avoid attending to it.

Amulya (2004) defines reflection as "an active process of witnessing one's own experience in order to take a closer look at it, sometimes to direct attention to it briefly, but often to explore it in greater depth" (p. 1). A video recording of an event allows us to examine an experience after we have gone through it. Amulya emphasises, as others before her have done (notably Schön's ideas on reflection-on-action (1991) and Kolb's (1985) on experiential learning), how fundamental this practice, along with examination before and during an experience, is to learning.

\section{“Good Enough” philosophy and learning technologies}

Educational developers have a responsibility to encourage teachers to innovate; to try something that is new to them, or in a new context. Something that particularly resonates with this is the "Good Enough" philosophy, which has been effectively explained by Martin Weller (2010) and in 2009 by Robert Capps in Wired magazine (www.wired.co.uk) with specific reference to the Flipcam. Essentially, "Good Enough" philosophy is about sacrificing a little output quality for cost and convenience pay-offs. "Good Enough" technologies are relatively easy to set up and learn to use, and low in financial cost. The need for training courses, requests to central services and budget-holder authorisation are all barriers to innovation, which requires opportunities for casual experimentation. Weller's and Capps' ideas can be taken further to suggest that those who introduce staff to these technologies have a responsibility to demonstrate outcomes that are easily achievable. With video, this means using the simplest and most accessible tools available 
(e.g. Flipcam, smartphone), free video hosting tools, minimal editing, and avoidance of the more professional-looking transitions, titles and other effects. In the case being discussed here, the technology is being used not only to enabling learners' own reflection and learning, but also to demonstrate how a particular tool can be useful for this aspect of teaching and learning, and to encourage experimentation.

\section{Staff development for digital literacy}

While Bawden (2008) claims that digital literacy is "a topic whose terminology is very confused", there is still significant support for Paul Gilster's (1997) simple description of digital literacy as the current form of literacy itself, the ability to deal with information in today's dominant and emerging formats. Kress (2003) talks about the "new dominance of the image ... [and] the medium of the screen" (p. 1) over the prior dominance of writing and books. Dobson (2011) extrapolates from Kress's argument that the English curriculum should include learning how to communicate in these different modes. The year 2005 (2 years after the publication of Gunther Kress's Literacy in the New Media Age) saw the launch of Youtube (www.youtube.com), through which over 3 billion videos are viewed every day, with users uploading the equivalent of 240,000 full-length films every week. It can now be argued that moving image - that is video - is the current dominant format for information, or what Dobson (2011) terms "semiotic, meaning loaded forms".

With this in mind, Kress' (2003) and Dobson's (2011) arguments can be extrapolated further to suggest that curricula, including curricula in learning and teaching development, should include learning to communicate ones ideas and actions through moving image.

A JISC (2011) briefing paper in support of grant funding for digital literacy development states that "teaching practice is critical to the development of learners' own attitudes and capabilities," that is teachers who use current technologies appropriately with their students will be supporting the development of students' literacy. In the same vein, we can propose that professional development programmes that require teachers to use current technologies appropriately will support the development of teachers' digital literacy. Unsurprisingly, this arises not only within the JISC's arguments for supporting teaching staff in digital literacy development: "Interventions in CPD ... can have a long-term impact on professional practice and consequently on the learning experience of future students" (p. 4), but also in the concluding recommendations for enhancing the digital literacy of teaching staff: "Professional development frameworks are a valuable tool for embedding new expertise and practice" (p. 25).

The Learning Literacies in a Digital Age report commissioned by the JISC (LLiDA 2009) concluded that "digital literacies are developed and progressed most effectively when technologies are integrated into authentic activities that fulfil educational or scholarly goals" (Messages and Implications). Westerman and Barry (2009), in their evaluation of the HEA-funded DEBUT project, which took an holistic rather than a skills-based approach to digital literacy development, also found that staff valued a situated, contextualised approach in learning to use digital tools. 


\section{Jordan}

\section{Discussion of the benefits of using video for reflection and feedback Exposure to alternative perspectives of ourselves and others}

Video offers an opportunity to view or review our actions and/or words from outside. In the same way as returning to an earlier blog post can enable a solution or an alternative path to become apparent, so can reviewing a video of ourselves reflecting on an experience or problem. As one APP participant articulated:

revisiting ... recordings is useful as I can continue to analyse what I said in that instance and assess its relevance as time passes and contexts change.

Watching oneself on video is not necessarily a pleasant experience, as proposed within the earlier discussion of Brookfield's (1995) ideas about reflection. It provides a great deal of feedback, and it is the richness of this feedback that can make for uncomfortable viewing, or cause people to be unwilling to be recorded in the first place. However, for those who tend to worry unnecessarily about their performance, the feedback from a video recording can be reassuring:

I have a tendency to worry about what I have said after the event, but recordings will either confirm that I have nothing to worry about or highlight points that need changing. (APP participant)

A video recording is, in one way at least, less fallible than our own memory, which, as Brookfield (1995) points out, distorts events according to the aspects we choose to augment and diminish. A video recording presents a version of an event that is less susceptible to this kind of adjustment, and can therefore mitigate against both "catastrophising" and complacency.

In reviewing a feedback exchange after the event, we can view it more objectively and with more time to think about what is being said. The reviewing of feedback is an activity that key theorists on reflection and experiential learning such as Amulya (2004), Schön (1991) and Kolb (1984) would support. During a live interaction, our focus will be on a range of other things - for example the noting down of idea from peers and tutors, or simply relief that the presentation is over. If we have the opportunity to watch a peer or colleague voicing their suggestions over again, we may take away something completely new. As one participant points out:

Quality recorded material won't exclude anything. When I am watching a live presentation, I can switch off or mishear certain points or attach a skewed meaning. Revisiting recordings is useful in overcoming this.

Another participant who took copious notes during a peer feedback session that was being recorded said:

I went back and watched the video a few weeks later, and realised how much was missing from my notes. Not only were there great suggestions being given that I just hadn't registered at the time (I was too busy writing!); there were also things I'd misinterpreted as I hadn't been able to capture the nuances in what people were saying.

\section{Focusing the mind}

Being spontaneously recorded visually and/or aurally is always a useful exercise for me as I am forced to "engage brain before opening mouth" in the same way I would in front of a group of strangers - hence I am more conscious about what I am saying. This in 
turn helps me remember what I've said and continue to mentally process it after the event. (APP participant)

While it may be assumed that increased self-consciousness generally has a negative impact on performance, the alternative perspective of fear as an emotion that will make the experience more memorable, and hone one's performance rather than hamper it, is interesting and helpful. The challenge is how to introduce this alternative perspective to those who only perceive a negative impact on their performance. One way of addressing this can be to introduce the recording of feedback sessions as a personal reflection tool, rather than something shared and owned by the whole group. Where the teacher takes responsibility for uploading videos, they should offer to set access passwords according to the learner's choice:

I am used to being recorded but there may still be an element of embarrassment while doing this, however technology now enables us to confront our "inner demons" in private. (APP participant)

\section{Freedom from the constraints of space and time}

In many cases video has been employed within the APP as an alternative to faceto-face interaction where participants have been unable to attend in person. While in many ways face-to-face - or at least synchronous - interaction is preferable (as discussed later on), on occasion the asynchronous approach has offered the affordance of a wider audience and greater range of feedback sources. One particular example was a participant who benefited from feedback from individuals beyond his tutor group who were doing related research.

The dispersal of learners is one of the biggest challenges facing post-compulsory education. Through the above example we can begin to see how this kind of activity could enhance the experience of an entire cohort of dispersed learners. However, as explained later on, the use of such tools should be planned for and embedded into the design of a course in order to ensure the learner experience is enhanced, rather than diminished by distance.

Any event that only exists in the physical world is exclusive to those who are in a certain place at a certain time. An example worth noting is a video produced by the author (Jordan 2009; http://goo.gl/eV5kS) for a conference display of "virtual posters". The videos were projected onto a wall as delegates networked. Very few delegates were actually watching the videos, and as the sound was muted they would not have gained much from doing so. However, posting the video up to a blog and linking to it from Twitter resulted in numerous "mentions", conversations and invitations to speak at other events. As yet, there is no way of tagging the physical interactions in space that compares to our ability to find, follow and amplify online memes.

\section{Visual impact}

The visual stimulus of video adds impact to a recording. When one considers the extent to which certain videos have "gone viral", compared with audience figures for popular audio recordings, it is clear that there is something that renders video significantly more attractive to the viewer. An important factor is the thumbnail 


\section{Jordan}

image, which usually displays a single frame from the video. This acts as a "taster" to draw viewers in (or equally, put them off). Clicking "play" on a video does not require the same leap into the unknown as it would do for an audio clip. It is perhaps worth bearing this in mind when using audio, as an illustrative still image can be a valuable accompaniment.

Having visual information in addition to audio also offers usability benefits:

At first I didn't see the point of having a video recording as opposed to just the audio. But using the video I realised how much easier it was to find the exact place I needed. (APP participant)

The practical downside of using video is that file sizes tend to be much larger than other media, so downloading and uploading require a reliable, fast internet connection. On the upside, recordings can be scanned efficiently, and as with diagrams, models and other visual aids, more information can be communicated per unit of time. Also, as another APP participant suggests: "Seeing the expressions on people's faces really helps make sense of the conversations". In combination, these factors can make videos a more palatable information format than audio.

\section{Discussion of the challenges of using video for reflection and feedback Reassuring the camera-shy: ethical considerations}

In the author's experience, responses to the suggestion of being recorded are usually neutral and sometimes negative; very rarely overly positive. It may be the case that people are reluctant to show enthusiasm for being recorded in case they appear narcissistic. This may contribute to teachers' perceptions that being recorded is not something that learners want.

There is some excellent information and advice on the JISC Digital Media website (http://goo.gl/Igdlz) which the author found useful in putting together an information sheet for participants as part of the preparation process for being recorded (Jordan 2010). This information sheet was deliberately written in informal language and went through several modifications with the increase in availability and clarity of information from the UK Intellectual Property Office (2009), particularly information relevant to Performers' Rights and online publication. On the flipside of the sheet, there are a number of questions designed to capture feedback on the usefulness of the information sheet itself. Feedback from APP participants indicated that the majority felt comfortable about being videoed having read this information.

In putting together this information sheet, one aim was to ensure participants were well-informed about the potential scope of the audience for any recording, while being reassured that relevant issues had been considered, their rights as performers would be respected and that videos could be password-protected or taken offline if required. Another aim was to ensure that selected videos could be used to enhance the learning experience of others, and to disseminate the outcomes of these practices, without the need to seek approval from individuals every time.

\section{Loss of the affordances of face-to-face dialogue}

In the previous section the example was given of a course participant who felt he benefited from peer feedback on his recorded project proposal. Another example 
where video was employed to mitigate against a participant's unplanned absence had a very different outcome; the participant felt that the feedback discussion that was recorded in response to his proposal video was too focused on "a throwaway remark" given at the start of the presentation and ignored the main points. Had the discussion taken place with the participant in the room, he would have been able to correct their interpretation and refocus the discussion. Nonetheless, the experience provided the stimulus for sustained reflection on the feedback process, which was evidenced in the participant's online research journal. After explaining how the misunderstanding arose, he wrote "I don't mean to criticise the observations or my peers at all, I just found it very interesting that I could be so misunderstood, which is ... something for me to reflect upon."

\section{Gaining technical experience}

A little experience may be required in order to get a "good enough" result with video. Concern about the intrusiveness of the camera may discourage the interruption of recordings to close a window, affix a tripod, adjust lighting or replace batteries. With more experience comes confidence and with it (usually) better recordings.

Video recording drains battery power quickly on a smartphone, and a Flipcam battery will only last for an hour's recording. Also, one is likely to spend up to twice the recording time transferring, editing and uploading files, so it is important to aim to record only what is needed. The ability to predict more accurately when to start and stop recording may develop with experience.

\section{Access to hardware}

Flipcams were employed for the majority of video recorded on the APP. While the quality of mobile phone video footage is usually "good enough", mobile phones typically have no tripod fixings and have to be held in the hand, which may be impractical or more intrusive for the subject. However, as the picture quality from mobile phones improves, they gain an edge over dedicated video devices like the Flip and the Kodak Zi8 because people tend to have their phones with them most of the time. Smartphones also offer the opportunity to capture video and upload directly to the web. As mobile connectivity and WiFi coverage improves, and it becomes easier to upload large files, the instant USB connection offered by the Flip and similar devices becomes less relevant. The retirement of the Flipcam range in April 2011 indicates the pace of this trend.

\section{Conclusions}

The intended learning outcomes of the APP at UAL focus on reflection, enquiry and/or evaluation. The use of self-reflection and the acquisition of feedback from peers - two of Brookfield's (1995) four lenses - are fundamental in achieving these outcomes.

It can be argued that video allows the augmentation of the existing, multiple benefits of these practices. Valuable, rich feedback is captured in its entirety, allowing learners to benefit fully and engage at greater length with the dialogue that enables the making of personal meaning and the transmission into specific action points 


\section{Jordan}

(Nicol and Macfarlane-Dick 2006). Learners are also led to evaluate how they themselves perform in a dialogic feedback situation, and assess what may be done in future in order to get more from the experience. As the effectiveness of these peer feedback events is increased, the reliance on the tutor to provide feedback is lessened, in turn promoting self-efficacy in the evaluation of practice.

There is also a "hidden curriculum" at work here. The embedding of these technologies within CPD programmes for staff has been researched by the HEA (Westerman and Barry 2009) and recommended by JISC (2011) as an appropriate approach to developing teachers' digital literacy. Several APP participants have begun to use video effectively with their own students, an outcome that was anticipated by the author and the progress of which is being followed with interest.

There are challenges and barriers to using video, which can be effectively addressed with a little research, experience and ongoing reflection. Hardware challenges are becoming less significant as personal gadgets become more efficient and increasingly capable of fulfilling multiple purposes.

It has been shown that the use of voice, particularly where augmented with moving image, can support learning in many ways. There are affective aspects; the way audio and video can help us to connect with people and emotions, and more practical benefits connected with the richness and reliability of information capture. In terms of the tools and techniques required to achieve a useful outcome, the predominant trends are changing rapidly and are likely to continue to do so. Therefore, it is vitally important that we use whatever is readily available, aim for nothing more than a "good enough" result and encourage our students and colleagues to do the same.

\section{Acknowledgements}

I would like to thank Ellen Sims and the other APP tutors for contributing their ideas, supporting mine and being generally enthusiastic about the effective use of learning technologies. Most importantly, I would like to thank the APP participants for their ongoing willingness to provide me with thoughtful, constructive feedback. Without their support this paper could not have been written.

\section{References}

Allen, D. W. \& Ryan, K. (1969) Microteaching, Addison-Wesley, Boston, MA.

Amulya, J. (2004) What is Reflective Practice?, Center for Reflective Community Practice, Massachusetts Institute of Technology, Cambridge, MA.

Bawden, D. (2008) 'Origins and concepts of digital literacy', in Digital Literacies; Concepts Policies and Practices, eds Lankshear, C. \& M. Knobel, Peter Long, NY, USA, pp. 17-32. Available at: http://sites.google.com/site/colinlankshear/DigitalLiteracies.pdf

Boud, D. (2000) 'Sustainable assessment: rethinking assessment for a learning society', Studies in Continuing Education, vol. 22, no. 2, pp. 151-167.

Brookfield, S. (1995) Becoming a Critically Reflective Teacher, Jossey-Bass, San Francisco, CA.

Capps, R. (2009) 'The good enough revolution: when cheap and simple is just fine', Wired magazine, [online] Available at: http://www.wired.com/gadgets/miscellaneous/magazine/1709/ff_goodenough

Crooks, T. J. (1988) 'The impact of classroom evaluation practices on students', Review of Educational Research, vol. 58, no. 4, pp. 438-481.

Dobson, S. (2011) 'Review of Gunther Kress' Literacy in the New Media Age', Seminar.net; International Journal of Media, Technology and Lifelong Learning, vol. 7, no. 1. Available at: seminar.net/index.php/vol-7-issue-1-2011 
Gilster, P. (1997) Digital Literacy, John Wiley, New York.

JISC. (2011) Developing Digital Literacies: Briefing Paper in support of JISC Grant Funding 4/11, [online] Available at: http://www.jisc.ac.uk/media/documents/funding/2011/04/ Briefingpaper.pdf

JISC Digital Media Resources. Available at: http://www.jiscdigitalmedia.ac.uk/crossmedia/ advice/copyright-and-other-rights-for-creating-time-based-media-resources/

Jordan, L. (2009) 'Engaging students in the curriculum through the use of blogs; how and why?', Proceedings of the Fourth International Blended Learning Conference, University of Hertfordshire, Hertfordshire. Available at: http://www.herts.ac.uk/fms/documents/ teaching-and-learning/blu/conference2009/Lindsay_Jordan.wmv

Jordan, L. (2010) Video and Audio Recordings; Frequently Asked Questions, [online] Available at: http://goo.gl/q1ePK

Kolb, D. A. (1985) Experiential Learning: Experience as the Source of Learning and Development, Prentice Hall, London.

Kress, G. (2003) Literacy in the New Media Age, Routledge, London.

LLiDA (2009) Learning Literacies in a Digital Age, [online] Available at: http://caledonian academy.net/spaces/LLiDA/index.php?n=Main.MessagesAndImplications

McConnell, D. (2002) 'The experience of collaborative assessment in e-learning', Studies in Continuing Education, vol. 24, no. 1, pp. 73-92.

Nicol, D. J. \& Macfarlane-Dick, D. (2006) 'Formative assessment and self-regulated learning: a model and seven principles of good feedback practice', Studies in Higher Education, vol. 31, no. 2, pp. 199-218.

Schön, D. A. (1991) Educating the Reflective Practitioner: Towards a New Design for Teaching and Learning in the Professions, Jossey-Bass, San Francisco, CA.

The Khan Academy. Available at: www.khanacademy.org

UK Intellectual Property Office. (2009) Performers' Rights, [online] Available at: http:// www.ipo.gov.uk/types/copy/c-otherprotect/c-performer.htm

Weller, M. (2010) 'The lamb formula: good enough?', The Ed Techie, [online] Available at: http://nogoodreason.typepad.co.uk/no_good_reason/2010/11/the-lamb-formula-goodenough.html

Westerman, S. \& Barry, W. (2009) 'Mind the gap: staff empowerment through digital literacy', in Transforming Higher Education through Technology Enhanced Learning, Higher Education Academy, HEA, York, UK, pp. 111-134. Available at: http://www.heacade my.ac.uk/resources/detail/ourwork/learningandtech/transforming_he_through_technology_ enhanced_learning 